\title{
Effect of cataract extraction on the pupil response to mydriatics
}

\author{
MARY V GIBBENS, ' R GOEL, ${ }^{2}$ AND S E SMITH ${ }^{1}$ \\ From the Departments of ${ }^{1}$ Clinical Pharmacology and ${ }^{2}$ Ophthalmology, St Thomas's Hospital, London \\ SE1 7EH
}

Summary Pupil diameters in the dark, in the light, and after mydriasis with tropicamide+ phenylephrine have been measured in 25 patients before and six months after cataract surgery. The aphakic pupil showed reduced mobility as evidenced by a smaller diameter in the dark and a larger one in the light. In patients who had intracapsular extraction or extracapsular extraction with intraocular lens implantation the pupils dilated less well than preoperatively. The difference in response to mydriatics is of practical importance in the assessment and treatment of peripheral retinal disorders in aphakic and pseudophakic eyes.

It is a clinical impression that aphakic eyes do not dilate as well as phakic eyes to the topical application of mydriatics, so that the view of, and access to, the peripheral fundus is limited. The aim of this study was to test this impression. The investigation was conducted at a time when both intracapsular cataract extractions (ICCE) and extracapsular cataract extractions (ECCE) were being conducted routinely, with and without intraocular lens (IOL) implantation.

\section{Patients and methods}

Twenty-five patients (10 male, 15 female), aged 4684 years, were recruited to the study. None was diabetic or receiving medication which might affect function in the autonomic nervous system. Each attended on two occasions, immediately before and approximately six months after cataract extraction.

At each attendance the pupil diameters were measured in the dark and under bright continuous illumination by infrared television pupillography. ${ }^{1}$ This illumination, from two fluorescent lamps placed $50 \mathrm{~cm}$ from the patient, was of a brightness comparable to that needed for ophthalmic practice. Pupils were measured before and $60 \mathrm{~min}$ after application of mydriatic eyedrops ( 1 drop of each drug bilaterally): tropicamide $0.5 \%$ and phenylephrine $10 \%$ (Minims, Smith and Nephew Pharmaceuticals). Mydriatics

Correspondence to Professor S E Smith. were not instilled postoperatively into the eyes of one patient who had an iris-supported lens implanted.

Some data were not obtainable where: (1) the cataract was sufficiently white to preclude pupillographic measurements (in which good pupil/iris contrast is crucial); (2) the diameter of the pupil was too small to register $(<1.9 \mathrm{~mm})$; (3) light reflection from the cornea obscured the view.

The results of the experiment were assessed only where paired comparisons (postoperative versus preoperative) could be made; they were evaluated by Student's paired $t$ tests by standard methods. The study was approved by the Ethics Committee of West Lambeth Health Authority.

\section{Results}

Sixteen of the 25 patients, aged 70.6 (2.4) yr (mean, SEM), underwent ECCEs, seven of these with posterior chamber IOL implantation. Nine patients aged $67 \cdot 2(3 \cdot 2)$ yr underwent ICCEs, none with IOL implant. Twelve patients received peripheral iridectomies. The operations were carried out by several different surgeons. None of the postoperative eyes showed evidence of posterior synechiae, peripheral anterior synechiae, iris root adhesions to the incision, vitreous or capsule strands to the incision, or pupil capture, any of which complications might have resulted in impaired iris mobility. ${ }^{2-5}$

Fig. 1 shows the mean pupil diameters of the operated and the fellow eyes in both darkness and 
Fig. 1 Pupil diameters (mean $\pm S E M$ ) in the dark, in the light, and following application of mydriatics in patients before and after ECCE (extracapsular cataract extraction without intraocular lens implant, 9 eyes), ECCE/IOL (extracapsular cataract extraction with intraocular lens implant, 7 eyes), ICCE (intracapsular cataract extraction without lens implant, 9 eyes), and CONTROL (unoperated, 22 eyes).

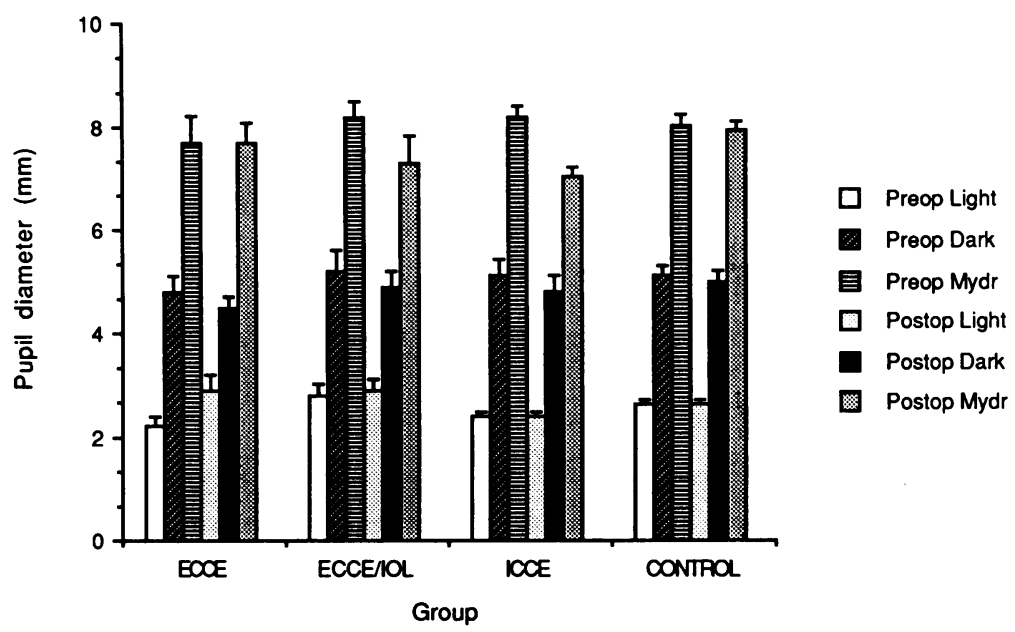

bright illumination before mydriasis and $60 \mathrm{~min}$ after application of mydriatics. At this latter stage for all eyes the mean change in diameter with the bright illumination was less than $0.01 \mathrm{~mm}$, indicating that the light reflex had been totally abolished. There was no significant difference between the preoperative pupil diameters of the eyes which subsequently underwent the three operative procedures.

The resting diameter in the dark of the aphakic eyes was $0.3 \mathrm{~mm}$ smaller than preoperatively $(\mathrm{p}<0.0025)$, whereas that in the fellow control eyes was unchanged. By contrast under bright illumination the resting diameter of the aphakic eye was $0 \cdot 3$ $\mathrm{mm}$ larger than before surgery $(\mathrm{p}<0.01)$, whereas that of the fellow eyes was unchanged. Cataract extraction was therefore associated with a small reduction in iris mobility.

The final diameter of the aphakic and pseudophakic eyes after mydriasis was $0.7 \mathrm{~mm}$ less than preoperatively $(p<0.0025)$, whereas in the fellow control eyes there was no change. The final diameter after mydriasis of the nine eyes which had undergone ECCE without IOL implantation was not significantly different from preoperatively. With posterior chamber IOL implantation (seven eyes), however, the final diameter after mydriasis was $0.9 \mathrm{~mm}$ smaller than preoperatively $(p<0.02)$. Similarly, in the nine eyes which had undergone ICCE the diameter after mydriasis was $1.2 \mathrm{~mm}$ smaller than preoperatively $(p<0.02)$. Among these affected groups three out of 16 patients' pupils dilated to final diameters of $6 \mathrm{~mm}$ or less.

\section{Discussion}

This study has shown that in the dark the resting aphakic pupil is smaller than preoperatively but that in the light it constricts less. Furthermore the aphakic pupil responds less to mydriatics, reaching a smaller final diameter than preoperatively. In three of our cases the pupils did not dilate beyond $6 \mathrm{~mm}$, a size which is critically small for examination or treatment of the peripheral retina.

The explanation for these findings probably lies with the amount of iris trauma occurring at operation. ${ }^{4}$ Damage to the sphincter pupillae will result in a reduced ability of the iris to constrict in response to light. Conversely, damage to dilator fibres will reduce the response to mydriatic drugs. This series suggests that the amount of iris trauma, as indicated by poor response to mydriatics, was greatest for ICCEs, followed by ECCEs with IOLs, and least for ECCEs alone. between preoperative and postoperative mydriatic response, which suggests that nucleus expression and soft lens matter aspiration causes little direct iris trauma. Greater trauma is understandably caused by the implantation of a posterior chamber IOL. Since this study was conducted at a time when some surgeons were converting from ICCEs to ECCEs with IOLs, it is likely that this degree of trauma will be further lessened by improved skills, techniques, lens design, and instrumentation.

All the ICCEs underwent peripheral iridectomy, which of necessity causes direct iris trauma. This probably accounts for the poorer response to mydriatics in this group. Since to omit the peripheral iridectomy would increase the risk of pupil-block glaucoma ${ }^{6}{ }^{6}$ decreased pupil mobility must be consurgery. The risk of retinal detachment following cataract surgery is up to $2 \%^{7}$ and is greater following intracapsular than extracapsular surgery. ${ }^{6}$ The
Eyes undergoing ECCE alone showed little change sidered the inevitable response to intracapsular 
poorer ability of the former cases to respond to mydriatics may in practice compound the problem.

In conclusion, the study confirms the clinical impression that aphakic and pseudophakic pupils dilate less well than phakic pupils. This may be of considerable relevance when attempting to examine or treat the peripheral retina of the aphakic eye, especially following intracapsular cataract extraction.

MVG was supported by a grant from the Research (Endowments) Committee of West Lambeth Health Authority.

\section{References}

1 Smith SE, Smith SA, Brown P, Fox C, Sonksen PH. Pupillary signs in diabetic autonomic neuropathy. Br Med J 1978; ii: 924-7.

2 Jaffe NS. Cataract surgery and its complications. 3rd ed. St Louis: Morsby, 1981.

3 Dobree JH. Cataract. In: Sorsby A, ed. Modern ophthalmology. 2nd ed. London: Butterworths, 1972: 4.

4 Roper-Hall MJ. The lens. In: Roper-Hall MJ, ed. Stallard's eye surgery. 6th ed. Bristol: Wright, 1980.

5 Steele ADMcG, Kirkness C. Intraocular lens implantation. In: Miller S, ed. Clinical ophthalmology. London: Wright, 1987.

6 Kanski J. Cataract surgery. In: Miller S, ed. Clinical ophthalmology. London: Wright, 1987.

7 Scheie HG, Morse PH, Aminlari A. Incidence of retinal detachment following cataract extraction. Arch Ophthalmol 1973; 89: 293-5.

Accepted for publication 20 October 1988. 